\title{
The Power of Knowledge Facing the Power of Position: Case Study about the Conflict of Power
}

\section{Adham AlArbeed*}

Aga Khan University, Karachi, Pakistan

\begin{abstract}
Case Studies, as teaching strategies, have been described as an explanation of real situations confronted by a person or persons in an organization. It has been featured as a way to aggravate the learners' critical thinking; to apply theory into practice; to train learners toward decision making; to enhance learner's cooperative learning skills; and to build partnerships among learners and teachers. This paper presents a case study about the conflict of power. The real names of the persons involved in the scenario had been replaced with vague ones. This is to ensure the rigor of this work. The aim of this paper is to describe a situation in which leaders in nursing administrative positions faces a lot. Besides, the paper aims to provide a logical approach toward dealing with such situations. Furthermore, it aims to activate the critical thinking of the readers through providing a list of questions at the end of the paper in order to generate a discussion which in its turn enhances the learning process.
\end{abstract}

Keywords: Case study; Conflict of power; Nursing administration; Nursing documentation; Medication administration

\section{Introduction}

Finally, she reaches her home. She sits on her rocker chair and starts swimming back in her thoughts into her day events. Susan was a nurse with bachelor degree and she had shifted newly to her new position as a clinical instructor. This was due to degree she has and the staff shortage problem in which the hospital is facing. From the beginning she felt threatened by her nursing director's attitude and behavior. She realized that this is due to what she heard about her boss and it maybe or maybe not presents her boss reality. Susan was a critical person and she decided to be rational toward judging people. This is through waiting the events to show her boss reality.

Earlier at the morning of that busy day an incident occurred in one of the hospital departments. Rana 'a staff nurse in the hospital' received a verbal order from a doctor to administer medication for one of the patients under her responsibility. The medication 'Heparin' was improper to be described in the usual dose without farther investigation, because, although the patient first health problem was deep vein thrombosis, she also has a stomach ulcer and she was using aspirin on daily basis. Rana gave the medication to her patient. After a while the patient started to complain from severe complications such as sudden severe headache, weakness, confusion, problems with vision, problem with speech, chest pain, trouble breathing, and severe epistaxis. The nurse immediately asked for the doctor help. Surprisingly, the doctor started to blame her for giving the medication to the patient and he denies giving the medication order. The nurse could not prove the doctor order because it was a verbal one without documentation at all. As a result for that, she suspended from her job. An internal investigation started later during the day appears that it was the doctor mistake because in fact he did gave the order to Rana. Yet, that was without a proper documentation from any of them the doctor or the nurse. Thus, Rana's suspension remains.

Toward this incident, Zinab 'Susan Director' decided to make an announcement for all the nurses to instruct them to be aware in case of medication administration in order to avoid mistakes. Then, she put the responsibility on the nurses' shoulders in such cases if it happens again. With all the respect to her boss experience, Susan privately discussed her decision with her. Susan suggested that there is a need for more in depth analysis to the problem. This is to ensure avoiding its repetition. Zinab answer was very short and clear. She said "I did enough".

\section{Susan position}

At her rocker chair, Susan started analyzing the incident. She said: My manger made a decision toward the incident. This decision, even that it is a right one somehow, was inappropriate for many reasons. First, her decision making approach did not follow scientific or logical steps. Following such steps is very important due to many reasons, like logical decision making ensures lowering incidents repetition rates. Second, through following the autocratic style of management, she did not allow herself to get the benefits of sharing others in the decision making process.

\section{Analyzing the reasons behind Zinab decision}

Susan started to go deeper in her thoughts. She tried to be a critical person through following the logical decision making process her. She decided that if she is going to take any action, she will not allow herself to fall in the same mistake that Zinab made. She stated that "I will assess, analyze, diagnosis, plan, then intervene." She remembered Clarkson (2009) [1] statement "Nurses progressing to management positions remain largely uneducated, unsupported and with no or very little orientation or succession planning pertaining to management skills and knowledge" (p.6). My boss was one of the senior nurses with twenty-five years of experience most of it in the clinical work. She just became in a managerial position two years ago. She had graduated from a two years nursing program and she did not receive any training or education toward nursing leadership and management. Clarkson

*Corresponding author: Adham AlArbeed, B.Sc., RN. M.Sc. Student at the Aga Khan University, Karachi, Pakistan, Tel: 009617151 8641; E-mail: Adham.arbeed@gmail.com

Received July 06, 2015; Accepted August 26, 2015; Published September 04 2015

Citation: AlArbeed A (2015) The Power of Knowledge Facing the Power of Position: Case Study about the Conflict of Power. J Clin Med Genom 3: 123. doi: 10.4172/2472-128X.1000123

Copyright: () 2015 AlArbeed A, This is an open-access article distributed under the terms of the Creative Commons Attribution License, which permits unrestricted use, distribution, and reproduction in any medium, provided the original author and source are credited. 
(2009) [1] mentioned this problem in nursing leadership "often the most senior nurse in the ward may have developed skills in leadership. It is these informal leadership skills that are relied upon to fulfill the management role" (p. 6). Thus, my boss mostly has an educational cap. Clarkson (2009) [1] stated about this issue that "There is an educational gap between nurses moving from acute care delivery to the manager position" (p. 6). This educational cap caused lack of the awareness for the importance of following logical decision making approaches. Now, I become quite sure that the main reason behind my boss improper or misguiding decision making approach was the lack for a proper education in leadership and management, Susan reiterated.

Yet, "why she refused to share others through the process of making the decision?" Susan asked herself. She answered "maybe, as I heard, she is an autocratic leader." I remember what Huston (2008) [2] wrote in his book. He explained that future nurses leaders may improve the quality of their decisions through communicating with experts like mangers, scientists, researchers, health care professionals, and even attorneys and industry executives. Moreover, I remember Jones, Rebecca and Patronis (2007) [3] statement about transformational leaders. They stated that "Participative and transformational leaders enter into relationships with the professionals in their organizations. They share information, discuss values, and collaborate on decisions. The self-esteem of team members correlates with involvement with decision making" (P. 24). The issue became clear now. My boss is an autocratic leader, no doubt about that. When she said "I did enough" she provided clear evidence that she did not have the knowledge about the benefits of sharing through decision making process.

\section{Diagnosing the problems}

Susan started to identify the main and the sub problems in the incident. She said: "The main problem is what I have to do? Do I intervene supported by my knowledge or I do not due to my fear of my boss authority; since she already refused my suggestions." She further said: "There is a sub problem involved her. This is toward the medication administration documentation process and it is directly related to my work as a clinical instructor. Yet, without my boss approval, according to my job description, I cannot intervene."

\section{Planning for intervening}

Susan's dilemma was that she realized that she is facing a conflict of power. The power of her boss position was facing the power of her knowledge. This drove her to decide that it is the time to prepare a plan. She takes a paper and pencil and started drawing a framework for her future acts. She thought that, I can investigate the issue without my boss approval since it is my right to do that considering my job description. Then, I can write a proposal about the best approach for the solution. In this case, I will increase the chances of getting my boss approval for intervening if my investigation shows the need for that.

\section{Working within her position limitations}

The very next day, Susan started her investigation. She utilized the lunch time at the work place to make a focused group discussions with the staff nurses in the hospital. She kept writing down their responses summaries. From her focused group discussion summaries, Susan realized that the underpinning problems are the inadequate knowledge about the importance of documentation and a lack in the follow-up process for the nursing documentation. Furthermore, the inadequate knowledge about the importance of documentation appeared to be not an individual problem but a common one among all the nurses in the hospital. Moreover, the nurses in the hospital did not receive any education toward the importance of documentation. Besides, the follow up process for the nursing documentation was completely absent.

Since her objective is to find a way to prevent the reputation of such incidents in the future, Susan consulted the literature. In the published literature she found that, the best solution to deal with the inadequate knowledge about the importance of documentation among the nursing staff is to start immediate continuous learning courses. This is due to the fact that, continuous learning is essential for the continuous professional development. In addition, another intervention is suitable to be made, Susan said. This is through preparing a poster which contains the basic information about the importance of documentation and the nurse's responsibilities toward that. This poster is to be distributed for all the departments as an immediate response until the courses start.

For the absence of supervision toward the nursing documentation in the hospital, she decided to start establishing a new policy. After studying the patient files format and consulting the literature she was lucky to find an effective solution. The solution was a policy for double signature for each medication administration order. Thus, through relating the responsibility of each work with two nurses the mistakes happening probability go to the minimum. Susan did not invent this solution. She found it in the literature within the Saskatchewan registered nurses' Association (SRNA) guide. The SRNA guide (2007) [3] stated that "Independent double-checking is a safety strategy to reduce medication errors" (P. 9).

\section{Falling into the conflict}

One week after Rana's incident, Susan finished writing her intervening plan proposal. She decided to visit Zinab office the next day to present it. Early in the morning, Susan reached at her office. As usual, she started her daily preparations through checking her e-mail. She found an e-mail from Zinab. In the e-mail Zinab wrote "dear Susan, I would like you to follow the orders. It is not suitable to spend your time on a resolved issue. I think I was clear when I said that our work had been finished toward Rana's incident. Wish you will focus more on your assigned work in the future. Any further work on that incident will hold consequences on you". After reading Zinab e-mail, Susan gets disappointed. She started to think "what I have to do? In the first hand, if I obey the orders and a similar incident happened in the future it will be hard to forgive myself. Yet, if I did not follow the orders and continue with my plans of presenting my proposal to Zinab or the higher authorities my carrier will be affected badly.

\section{Requesting help}

Susan herself was new in her current position. She was enthusiastic for her work; yet, she was aware of the rigid work regulations at her hospital. She did not know what to do. She spent a lot of time thinking about "what is the best to be done?" Finally, she decided to write her story in a case study format. This is to request your help through asking you to answer the following question:

- Do you think my intervening plan was logically prepared? What modification do you suggest?

- Do you agree with my boss e-mail instructions, and why?

- Do you think I have to present my intervening proposal to my boss regardless to her e-mail, and why?

- Do you think it is better to approach higher authorities to present my proposal, and why? 
Citation: AlArbeed A (2015) The Power of Knowledge Facing the Power of Position: Case Study about the Conflict of Power. J Clin Med Genom 3: 123. doi: $10.4172 / 2472-128 X .1000123$

Page 3 of 3

\section{References}

1. Megan Clarkson (2009) leadership and management in nursing, concepts analysis, a research project presented in partial fulfillment of the requirements for the degree of Master of Nursing, Waikato Institute of Technology Hamilton, New Zealand.
2. Huston C (2008) Preparing nursing leaders for 2020. Journal of nursing management 16: 905-911.

3. Jones Rebecca A (2007) Nursing leadership and management: Theories Processes, and Practice (1sted) Philadelphia, USA: FA Davis Company Medication Administration: Guidelines for Registered Nurses, 2007/2003/2000, ThSaskatchewan Registered Nurses' Association (SRNA), Regina, Canada. 